\title{
BMJ Open After the diabetes care trial ends, now what? A 1-year follow-up of the RxING study
}

\author{
Yazid N Al Hamarneh, ${ }^{1}$ Luc Sauriol, ${ }^{2}$ Ross T Tsuyuki ${ }^{1}$
}

To cite: Al Hamarneh YN, Sauriol L, Tsuyuki RT. After the diabetes care trial ends, now what? A 1-year followup of the RxING study. BMJ Open 2015;5:e008152. doi:10.1136/bmjopen-2015008152

- Prepublication history for this paper is available online. To view these files please visit the journal online (http://dx.doi.org/10.1136/ bmjopen-2015-008152).

Received 9 March 2015 Revised 9 June 2015 Accepted 30 June 2015
CrossMark

\section{${ }^{1}$ EPICORE Centre, Department of Medicine, Faculty of medicine and Dentistry, University of Alberta, Edmonton, Alberta, Canada \\ ${ }^{2}$ Department of Health Economics, Sanofi Canada, Laval, Quebec, Canada}

\section{Correspondence to} Dr Yazid N Al Hamarneh, Yazid.AlHamarneh@ualberta. ca

\section{ABSTRACT}

Introduction: There is strong evidence that pharmacist care improves patients' glycaemic control. However, the sustainability and durability of such interventions beyond the research period is not known. RxING was the first trial of pharmacist prescribing in diabetes and it showed an improvement in glycated haemoglobin $(\mathrm{HbA} 1 \mathrm{c})$ of $1.8 \%$ over 6 months.

Objective: $1^{\circ}$ objective: To evaluate glycaemic control in the RxING study patients 12 months after the end of the formal study follow-up. $2^{\circ}$ objective: To assess the patients' risk of cardiovascular events in the next 10 years.

Methods: We contacted the participating pharmacists to check if the patients who participated in the RxING study are still taking insulin, the dose of insulin they are taking, and their $\mathrm{HbA1c}$. There were no mandated follow-up visits with the pharmacist after the study completion.

Results: A total of 100 patients with poorly controlled type 2 diabetes were enrolled in the original RxING study; 93 of them completed the study, while 83 participated in the 12-month follow-up. Seventy-five patients were still taking insulin, with the average dose increasing from 31.1 units (SD 18.4) at study completion to 37.4 units (SD 30.8$)(95 \% \mathrm{Cl}-13.3$ to $0.88, p=0.085)$. HbA1c was reduced from $9.1 \%$ (SD 1) at baseline to $7.3 \%$ (SD 0.9) at study completion (95\% Cl 1.4 to 2, p <0.001), and increased to $8.1 \%$ (SD 1.3) 12 months later $(95 \% \mathrm{Cl}-1.1$ to $-0.5, p<0.001$ vs study completion).

Conclusions: Twelve months after completing the intervention, approximately half of the glycaemic control gains were lost. This highlights the importance of structured follow-up with the pharmacist in this patient population.

Trial registration number: clinicaltrials.gov; Identifier: NCT01335763.

\section{INTRODUCTION}

The pharmacist's role in diabetes care is well supported in the literature. There is strong evidence, including systematic reviews and randomised controlled trials, that pharmacist interventions improve the patient's glycaemic control alongside other aspects of diabetes care such as medication adherence and

\section{Strengths and limitations of this study}

- This is the first study to evaluate the sustainability and durability of a pharmacist prescribing intervention for patients with poorly controlled type 2 diabetes beyond the research study period and it demonstrates the importance of ongoing structured pharmacist intervention on glycaemic control in patients with poorly controlled type 2 diabetes.

- We did not have any data on the patients' cholesterol/high-density lipoprotein ratio and this could affect their risk of cardiovascular events in the next 10 years (which is a surrogate marker): therefore, we used a ratio ' 4.9 ' which makes no contribution to the overall risk and assumed that there were no changes to this ratio over time to avoid any effect those changes may have on the risk of cardiovascular events in the next 10 years.

- We did not construct formal methods to track pharmacist follow-up visits beyond study completion.

knowledge about the disease and its complications. ${ }^{1-5}$

The RxING study took this evidence one step further, assessing the effect of a community pharmacist independent prescribing intervention on glycaemic control in patients with poorly controlled type 2 diabetes. ${ }^{6}$ The study showed that such intervention reduced patients' glycated haemoglobin (HbA1c) from $9.1 \%$ (SD 1) at baseline to $7.3 \%$ (SD 0.9 ) at 26 weeks (an absolute reduction of $1.8 \%, 95 \%$ CI 1.4 to $2, \mathrm{p}<0.001)$, and fasting plasma glucose was reduced from $11 \mathrm{mmol} / \mathrm{L}$ (SD 3.3) at baseline to $6.9 \mathrm{mmol} / \mathrm{L}$ (SD 1.8) at 26 weeks (an absolute reduction of $4.1 \mathrm{mmol} / \mathrm{L}, 95 \%$ CI 3.3 to $5, \mathrm{p}=0.007)$.

The sustainability and durability of such interventions beyond the research study period is not known, as intervention studies in diabetes usually last between 3 and 24 months. $^{2}$ There is little information about the long-term effect of pharmacist 
interventions in diabetes, particularly with prescribing interventions. As such, we conducted a 12-month follow-up of the RxING study patients to evaluate their glycaemic control 12 months after completing the study. The secondary objective was to assess the risk of cardiovascular events in the next 10 years 12 months after completing the study.

\section{METHODS}

The methods of the RxING study are reported elsewhere. ${ }^{6}$ Adult patients with poorly controlled type 2 diabetes (HbA1c between 7.5 and $11 \%$ ) despite receiving oral hypoglycemic agents, were recruited through 12 community pharmacies across Alberta, Canada. ${ }^{6}$ Community pharmacists, who had their independent prescribing authority, prescribed 10 units of insulin glargine at bedtime for these patients and asked them to titrate their dose by 1 unit/day until they reached a fasting plasma glucose of $5.5 \mathrm{mmol} / \mathrm{L}$. Patients were followed up at 2, 4, 8, 14, 20 and 26 weeks by their community pharmacists to provide ongoing care and address any issues regarding the treatment. HbAlc was measured at the pharmacy using point of care testing (DCA Vantage, Siemens, Tarrytown, New York, New York, USA) at baseline, 14 and 26 weeks. ${ }^{6}$

Twelve months after completing the study, we contacted the participating pharmacists to check if the patients who participated in the RxING study are still taking insulin, the dosage of insulin they are taking and their HbAlc level. There were no mandated follow-up visits with the pharmacist after the study completion.

Pharmacists have used the Provincial Electronic Health Records (Alberta Netcare) to obtain information about the most recent HbAlc level and their own medication records to check if the patient is still taking insulin glargine and its dosage.

We also calculated the patients' risk of cardiovascular events in the next 10 years using the UK Prospective Diabetes Study (UKPDS) calculator, with the assumption that the cholesterol/high-density lipoprotein (HDL) ratio is 4.9. This value was chosen because it makes no contribution to the overall risk, ${ }^{7}$ as we did not collect any data on the patients' lipid profiles.

The level of significance was set at 0.05 . The mean HbA1c between the end of the study and 12 months after completion was compared using paired test. Paired $t$ test and basic frequencies were used to analyse secondary outcomes and demographic and clinical characteristics, respectively.

\section{RESULTS}

A total of 100 patients with poorly controlled type 2 diabetes were enrolled in the RxING study. Ninety-three patients completed the study, 86 (93\%) of whom participated in the 12-month follow-up (figure 1).

The demographic and clinical characteristics of the patients are reported elsewhere. ${ }^{6}$ Table 1 reports some

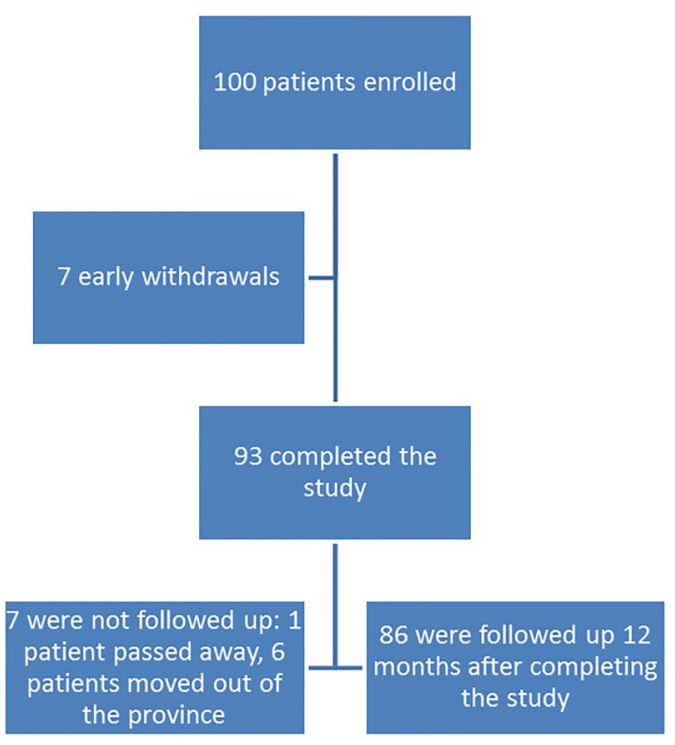

Figure 1 Patient's enrolment and follow-up flow chart.

demographic and clinical characteristics of patients at baseline, 6 months and 18 months after baseline.

Seventy-five patients $(88 \%)$ were still taking insulin 12 months after completing the study, with the average dose increasing from 31.1 units (SD 18.4) at study end to 37.4 (SD 30.8), a change of 6.3 units (95\% CI -13.3 to $0.88, \mathrm{p}=0.085$ ).

In the RxING study, HbAlc was reduced from 9.1\% (SD 1) at baseline to $7.3 \%$ (SD 0.9 ) at 26 weeks, a change of $1.8 \%$ (95\% CI 1.4 to $2, \mathrm{p}<0.001$ ). Twelve months after completing the study, HbAlc increased from $7.3 \%$ (SD 0.9) at study end to 8.1\% (SD 1.3), a change of $0.8 \%$ (95\% CI -1.1 to $-0.5, \mathrm{p}<0.001$; figure 2 ).

Patients' risk of cardiovascular events in the next 10 years was reduced from $31 \%$ (SD 17.3) at baseline to $26.7 \%$ (SD 14.5) at study end, an absolute reduction of $4.3 \%$ (a $14 \%$ relative reduction) (95\% CI 0.6 to 9.5, $\mathrm{p}=0.026$ ). Twelve months after completing the study, the risk of cardiovascular events in the next 10 years rose from $26.7 \%$ (SD 14.5) at study end to $30.75 \%$ (SD 15.5), an absolute increase of $4.05 \%$ (15\% relative increase) (95\% CI -0.09 to $0.005, \mathrm{p}=0.083$ ). This increase in risk was mainly caused by the worsening of glycaemic control.

\section{DISCUSSION}

Twelve months after completing a pharmacist prescribing intervention for patients with poorly controlled type 2 diabetes, approximately half of the glycaemic control gains and reduction in the risk of cardiovascular events in the next 10 years were lost. Despite impressive early gains in the intervention study, this highlights the need for an ongoing close follow-up of patients with diabetes.

The increase in HbAlc and the risk of cardiovascular events in the next 10 years can be explained by the lack of systematic follow-up by the pharmacist. We were informed by the participating pharmacists that patients 
Table 1 Patients' clinical and demographic characteristics

\begin{tabular}{llll}
\hline Characteristic & Baseline (N=100) & $\mathbf{6}$ months (N=93) & $\begin{array}{l}\text { 12 months postcompletion } \\
(\mathbf{N}=86)\end{array}$ \\
\hline Age (mean (SD)) & $64(10.4)$ & $64(10.5)$ & $65(10.4)$ \\
Diabetes duration (mean (SD)) & $10.2(7)$ & $10(6.7)$ & $10.4(6.8)$ \\
HbA1c \% (mean (SD)) & $9.1(1)$ & $7.3(0.9)$ & $8.1(1.3)$ \\
Insulin dose (mean (SD)) & - & $31.1(18.4)$ & $37.4(30.8)$ \\
Gender (\% male) & 58 & 57 & 57 \\
Ethnicity (\% Caucasian) & 89 & 89 & 88 \\
Smoking status (\% smokers) & 22 & 20 & 17 \\
\hline HbA1c, glycated haemoglobin. & & &
\end{tabular}

returned to receiving usual care after the study was completed. Until recently, there was no remuneration system for pharmacists in Alberta, Canada, which was considered as a barrier to follow-up. Disease progression and the lack of optimal insulin dose titration/stopping insulin may have also contributed to this increase. Indeed, it has been reported that patients with type 2 diabetes experience an average loss of $5 \%$ of insulin production capacity, per year, after diagnosis. ${ }^{8}$

The findings of this study highlight the impact of structured pharmacist intervention on glycaemic control in patients with poorly controlled type 2 diabetes. Patients' HbA1c improved by $1.8 \%$ (95\% CI 1.4 to 2, $\mathrm{p}<0.001)$ over 6 months while receiving the pharmacist's intervention; however, their HbAlc increased by $0.8 \%$ (95\% CI -1.1 to $-0.5, \mathrm{p}<0.001) 12$ months after completing the study. It is also important to note that the gains from the intervention were not completely lost 12 months after completing the study as the baseline HbA1c was $9.1 \%$ and $88 \%$ of the patients were still taking insulin. If maintained, this change from baseline has the potential to have a significant impact on future diabetes-related complications. ${ }^{7}$
This study is not without limitations. We did not have any data on the patients' cholesterol/HDL ratio and this could affect their risk of cardiovascular events in the next 10 years, which is a surrogate marker, therefore, we used a ratio ' 4.9 ' which makes no contribution to the overall risk ${ }^{7}$ and assumed that there were no changes to this ratio over time to avoid any effect those changes may have on the risk of cardiovascular events in the next 10 years. Also, no formal methods were constructed to track whether pharmacist follow-up visits had occurred beyond study completion. Pharmacists in Alberta, Canada have access to the Provincial Electronic Health Records (Alberta Netcare), where they can access important health information that was ordered by them or by other healthcare professionals. This system was created to improve the healthcare that is provided to the public. Key health information collected at different interactions with different healthcare professionals at a variety of locations gets recorded in the health records and then will be made available to all the healthcare professionals involved in the patient's care. ${ }^{9}$ This can affect the generalisability of the study results.
Figure 2 Glycated haemoglobin ( $\mathrm{HbA1c})$ change with the intervention and 12 months postcompletion * Dotted line indicates the completion of the intervention period.

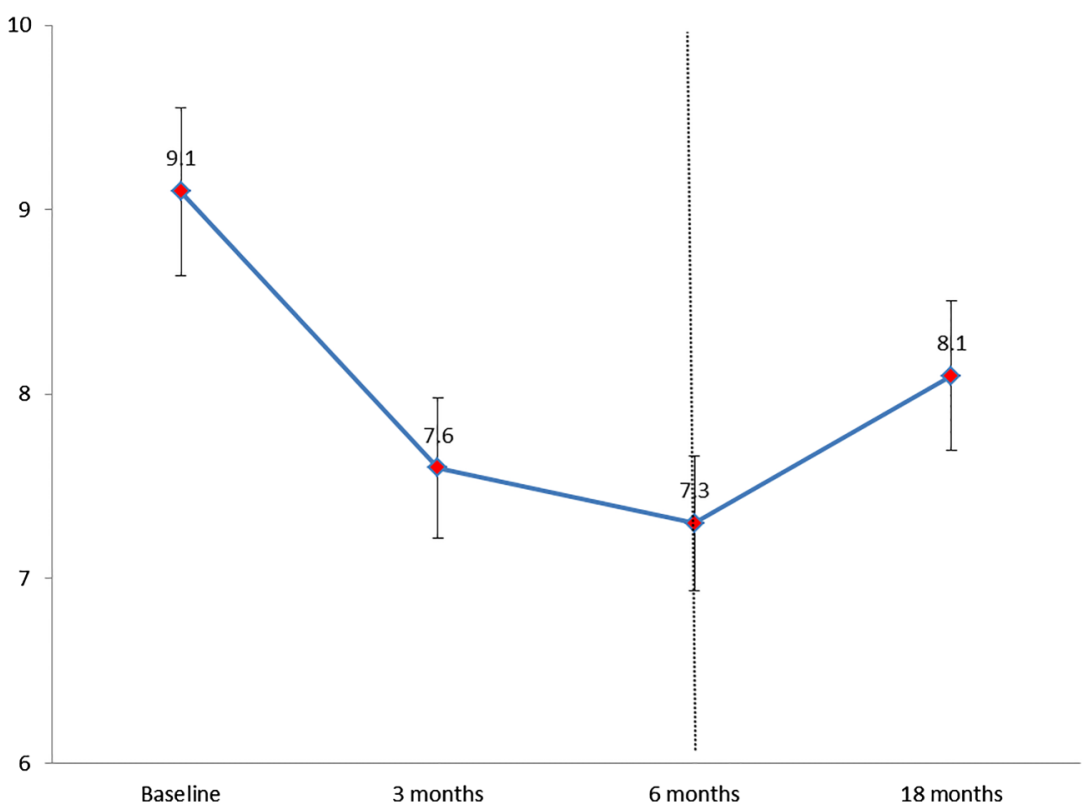


The findings of the RxING study took the evidence for the benefits of pharmacist care in diabetes one step further, as it proved that pharmacists can systematically identify patients with poor glycaemic control, educate and support them to achieve better outcomes on top of the known fact that insulin prescribing will improve glycaemic control. ${ }^{6}$ The 12-month postcompletion data suggest that systematic patient follow-up should be continued in order to maintain glycaemic control improvement. This supports the important role that pharmacists can play in improving glycaemic control in patients with poorly controlled type 2 diabetes.

Acknowledgements The authors would like to acknowledge the participation of the following pharmacists and pharmacies in making this study possible: Rick Siemens (London Drugs, Lethbridge), Darsey Milford (Turtle Mountain Pharmacy, Bellevue), Rita Bowron, Rami Chowaniec, Nader Hammoud, Carol Wei, Sheilah Kostecki (Safeway Pharmacy, Edmonton and Calgary), Anita Brown (Shoppers Drug Mart, Okotoks), Janelle Fox, Tony Nickonchuck (Walmart Pharmacy Cold Lake and Peace River), Rita Lyster (Rita's Apothecary and Home Healthcare, Barrhead) and Anita and Warren Dobson (Medicine Shoppe, Calgary).

Contributors RTT and YNA H took part in study concept and design. RTT and YNAH were involved in acquisition of data, analysis and interpretation of data and drafting of the manuscript. RTT, LS and YNAH were responsible for critical revision of the manuscript for important intellectual content. RTT and YNAH were responsible for statistical analysis. RTT, LS and YNAH provided administrative, technical and material support. RTT and YNAH undertook study supervision. All authors have made substantial contributions to the manuscript. YNAH had full access to all of the data in the study and takes responsibility for the integrity of the data and the accuracy of the data analysis.

Funding This research received no specific grant from any funding agency in the public, commercial or not-for-profit section.

Competing interests None declared.
Ethics approval Health Research Ethics Board of the University of Alberta (for the RxING study and the 1-year follow-up) and registered on clinicaltrials. gov (NCT01335763)

Provenance and peer review Not commissioned; externally peer reviewed.

Data sharing statement All obtained data have been analysed and reported in the manuscript. No additional data are available.

Open Access This is an Open Access article distributed in accordance with the Creative Commons Attribution Non Commercial (CC BY-NC 4.0) license, which permits others to distribute, remix, adapt, build upon this work noncommercially, and license their derivative works on different terms, provided the original work is properly cited and the use is non-commercial. See: http:// creativecommons.org/licenses/by-nc/4.0/

\section{REFERENCES}

1. O'Donovan D, Byrne S, Sahm L. The role of pharmacists in control and management of type 2 diabetes mellitus; a review of the literature. J Diabetol 2011;1:5-21.

2. Wubben DP, Vivian EM. Effects of pharmacist outpatient interventions on adults with diabetes mellitus: a systematic review. Pharmacotherapy 2008;28:421-36.

3. Armour CL, Taylor SJ, Houriham F, et al. Implementation and evaluation of Australian pharmacists' diabetes care services. $J$ Am Pharm Assoc 2004;44:455-66.

4. Fornos JA, Andres NF, Andres JC, et al. A pharmacotherapy follow-up program in patients with type-2 diabetes in community pharmacies in Spain. Pharm World Sci 2006;28:65-72.

5. Krass I, Armour CL, Mitchell B, et al. The pharmacy diabetes care program: assessment of a community pharmacy diabetes service model in Australia. Diabet Med 2007;24:677-83.

6. Al Hamarneh YN, Charrois T, Lewanczuk R, et al. Pharmacist intervention for glycaemic control in the community (The RxING study). BMJ Open 2013;3:e003154.

7. Stevens RJ, Kothari V, Adler Al, et al. The UKPDS risk engine: a model for the risk of coronary heart disease in Type II diabetes (UKPDS 56). Clin Sci 2001;101:671-9.

8. Lebovitz HE. Insulin secretagogues: old and new. Diabetes Rev 1999;7:139-53.

9. Alberta Health. Why create an EHR. 2015[http://www.albertanetcare. ca/WhyEHR.htm] (accessed 3 May 2015) 